\title{
Evaluation of Child Anxiety Prior to Dental Care by Means of Modified Venham Picture Test, RMS Pictorial Scale and Facial Image Scale Tests
}

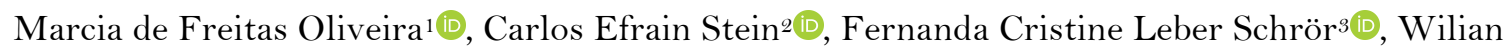 \\ Ricardo Keske ${ }^{3}$ (D)
}

\begin{abstract}
${ }^{1}$ Department of Dentistry, Regional University of Blumenau, Blumenau, SC, Brazil.
${ }^{2}$ Department of Mathematics, Regional University of Blumenau, Blumenau, SC, Brazil.

${ }^{3}$ Private Practice, Regional University of Blumenau, Blumenau, SC, Brazil.
\end{abstract}

Author to whom correspondence should be addressed: Marcia de Freitas Oliveira, Rua São Paulo, 2171, Itoupava Seca, Blumenau, SC, Brazil. 89030-001. Phone: + 5547332 1-7324. E-mail: marciaoliveira@furb.br.

Academic Editors: Alessandro Leite Cavalcanti and Wilton Wilney Nascimento Padilha

Received: 10 July 2019 / Accepted: 28 February 2020 / Published: 24 March 2020

How to cite this article: Oliveira MF, Stein CE, Schrör FCL, Keske WR. Evaluation of child anxiety prior to dental care by means of Modified Venham Picture Test, RMS Pictorial Scale and Facial Image Scale Tests. Pesqui Bras Odontopediatria Clín Integr. 2020; 20:e5068. https://doi.org/10.1590/pboci.2020.052

\begin{abstract}
Objective: To evaluate child anxiety prior to dental care; to compare the results obtained by applying different anxiety tests and to assess whether anxiety is related to age or gender, and to identify which test children find to be more attractive and easier to understand. Material and Methods: The research was performed with 30 children of both genders and age group of 4-9 years distributed into Group $1=$ children aged 4, 5 and 6 years and Group $2=$ children aged 7, 8 and 9 years. Modified Venham Picture Test (VPT), RMS Pictorial Scale (RMS-PS) and Facial Image Scale (FIS) were the anxiety evaluation tests used. For statistical analysis, the Shapiro Wilk Normality test, Spearman correlation and the Independent Proportions test were used. Results: Modified VPT identified 70\% anxiety-free children, RMS-PS 90\%, and FIS $87 \%$. RMS-PS and FIS scores had moderate correlation (51\%). Regarding age groups, no significant difference was found between proportions of group 1 and group 2. According to gender, in 11 girls, the modified VPT test identified $3(27 \%)$ with some anxiety degree; RMS-PS test identified $1(9 \%)$ and FIS test $2(18 \%)$. In 19 boys, modified VPT test identified $6(32 \%)$ with some anxiety degree; RMS-PS test identified $2(11 \%)$ and the FIS test $2(11 \%)$. The test that was the easiest to understand was the modified VPT (54\%) and regarding attractiveness, modified VPT and RMS-PS presented similar results, $40 \%$ each. Conclusion: All three tests were able to identify anxiety prior to dental care. The evaluation of results showed that the more the children could identify themselves with the test, the more they found it to be easy and attractive.
\end{abstract}

Keywords: Behavior and Behavior Mechanisms; Dental Anxiety; Pediatric Dentistry; Anxiety Scale. 


\section{Introduction}

Although dentistry is technologically developed, dental fear and anxiety are the most observed feelings in dental offices, both in children and adults. These are feelings that cause concern among professionals, as they impair the dentist-patient relationship, and can also result in interferences in the oral health care $[1,2]$.

The main factors that generate fear are: previous painful experience, lack of knowledge about procedures, office environment and negative ideas passed on by other people [3]. In dental care for children, dentists must be aware that fear is part of their development and that if behavior control techniques are not used, care can cause trauma throughout their lives [4].

In a comprehensive literature review published from 1982 to 2006 in the PubMed database, the prevalence of dental fear and anxiety (DFA) and dental behavior management problems (DBMP) in children and adolescents was assessed, as well as their relationship with age, gender, general anxiety, nature and general behavioral problems. The prevalence of DFA and DBMP was estimated at $9 \%$, with a decrease in prevalence with age. DFA / DBMP were more frequent in girls [5].

A cross-sectional analytical study in which 1,546 elementary school children were selected sought to assess the level of dental fear in schoolchildren and determine its relationship with dental caries. The children's fear research scale - sub-dental scale (EPMD-SD) was used to assess children's dental fear and caries activity was measured by the decayed, missing and filled permanent and deciduous teeth index (DMFT and dmft), according to criteria of the World Health Organization (WHO). The results showed that approximately $24 \%$ of children had high dental fear and $12.50 \%$ of them had severe dental fear. Girls had higher rate of serious dental fear than boys (20\% vs 5\%). Caries severity was significantly increased in children who had higher fear scores. It was observed that dental fear has direct relationship with permanent decayed teeth and inverse relationship with restored permanent teeth [6].

Interpreting the behavior of the pediatric patient enables the dentist to use appropriate techniques for the management of a particular child. Knowing the child's behavior, personality and psychological characteristics will significantly increase treatment successfulness [7].

Therefore, the analysis of child's behavior prior to dental care will enable the use of appropriate care techniques for each child, according to their emotional state. To assist in this behavior interpretation, choosing anxiety tests aimed at children is a good option. For this choice, some criteria must be used, since attractiveness, acceptance and identification by the figure shown influence the reliability of responses.

In this context, this study aimed to assess children's anxiety before dental care through the modified Venham Picture Test (modified VPT) tests [8], RMS Pictorial Scale (RMS-PS) [9] and Facial Image Scale (FIS) [10]; to compare the results obtained by applying the tests and to assess whether anxiety is related to age or gender, in addition to identifying which test children consider to be the most attractive and easiest to understand.

\section{Material and Methods}

\section{Study Design and Sample}

The research was performed at the pediatric dentistry reception of the Regional University of Blumenau (FURB).

The sample was carried out for convenience by evaluating 30 children of both genders who came for dental care from September 2018 to May 2019, belonging to the age group of 4-9 years, and were distributed 
into the following groups: Group $1=$ children aged 4, 5 and 6 years and Group $2=$ children aged 7, 8 and 9 years.

\section{Data Collection}

While the child waited for care, a child identification form was completed and tests were applied separately. For each test, the child was asked how he / she was feeling at that moment, and should point to the figure that best represented his / her emotion. Initially, the modified Venham Picture Test [8] was applied, which consists of eight cards that were in accordance with the ethnicity and corresponding gender of the interviewed child (Figures 1 to 4). Each card has two figures, an "anxious" figure and a "not anxious" figure. The figure that, in each pair, revealed the negative feeling was assigned one point in the assessment. The sum of the scores of all pairs of figures can vary from zero to eight, with zero representing anxiety-free, one to three - low anxiety level, four to six - intermediate anxiety level and seven and eight - high anxiety level [11].

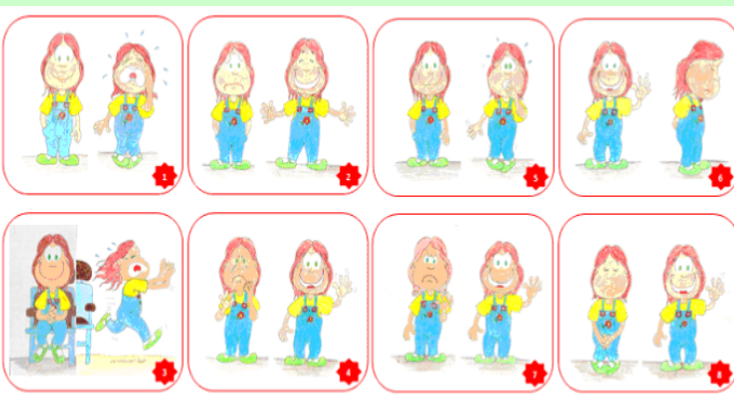

Figure 1. Modified VPT test (white girl) [8].

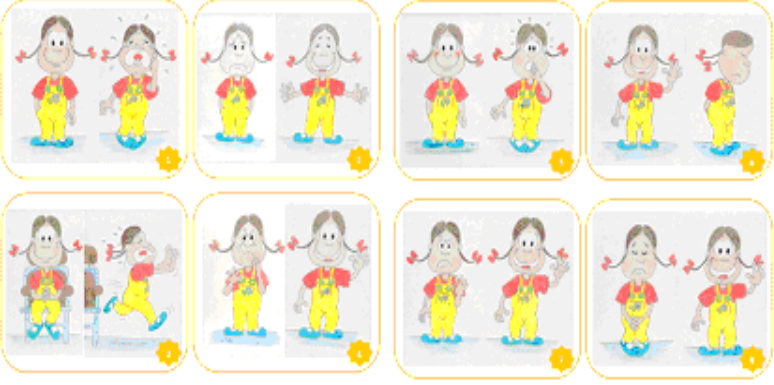

Figure 2. Modified VPT test (black girl) [8].

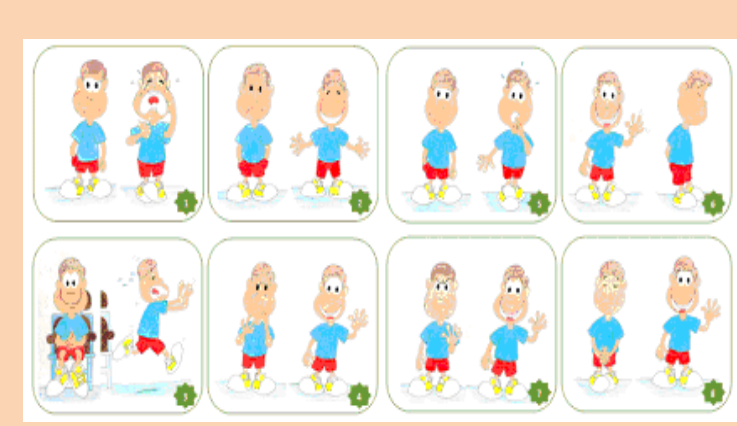

Figure 3. Modified VPT test (white boy) [8].

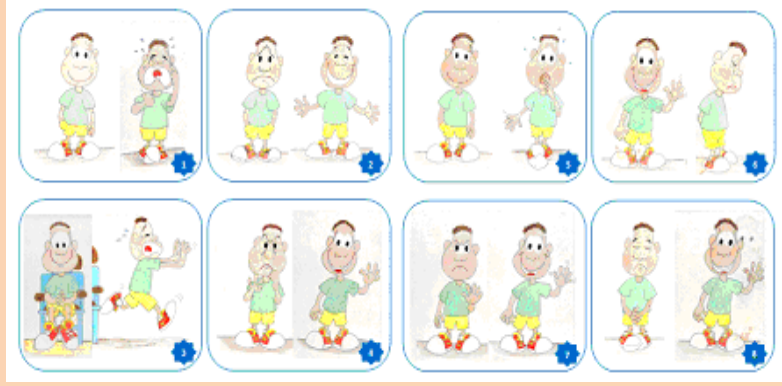

Figure 4. Modified VPT test (black boy) [8].

Then the RMS Pictorial Scale (RMS-PS) [9] was applied, which consists of 5 photographs of boy and girl faces that show emotional characteristics from very happy to very unhappy. Each photograph has a score, the first being the score 1 and the last score 5 (Figures 5 and 6). Finally, the Facial Image Scale (FIS) [10] was applied, which also contains figures of 5 faces, ranging from very happy to very unhappy. It has score from 1 to 5 , with 1 being very happy and 5 being very unhappy (Figure 7 ). After applying the tests individually, the child was asked to report which test he / she found easier to understand and which test he / she found more attractive. 


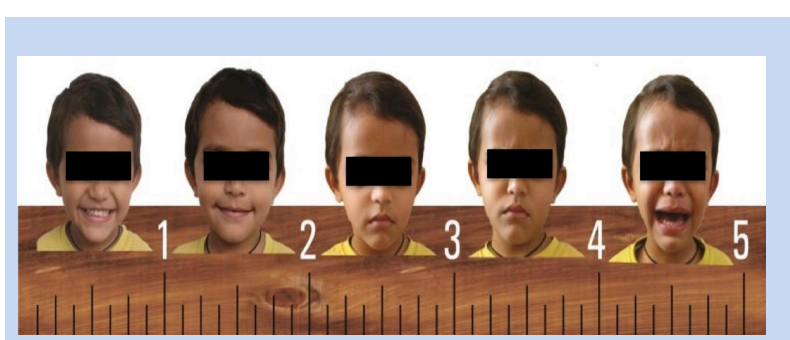

Figure 5. RMS Pictorial Scale (boy) [9].

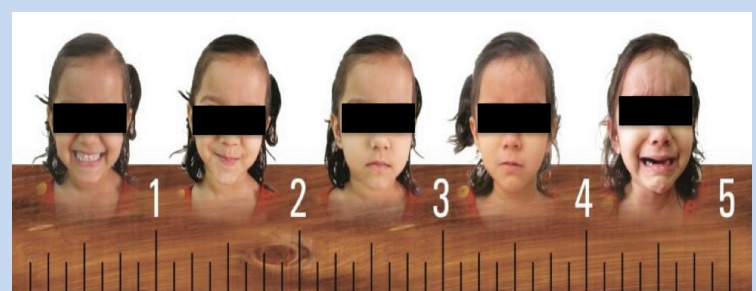

Figure 6. RMS Pictorial Scale (girl) [9].

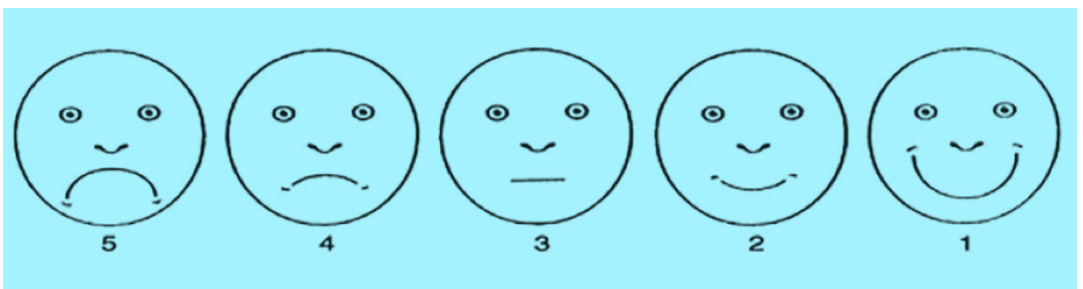

Figure 7. Facial Image Scale [10].

For data organization, the following scores were assigned for the modified VPT test: 1: Anxiety free; 2: Low anxiety level; 3: Intermediate anxiety level; and 4) High anxiety level. Regarding the RMS-PS test, for comparison purposes, the child was "very happy" and "happy" free from anxiety and assigned score 1. The test showed the following scores: 1: Very happy and happy (anxiety free); 2: Indifferent (low anxiety level); 3: Sad (Intermediate anxiety level); and 4: Very sad (high anxiety level). In the FIS test, for comparison purposes, the child was considered "very happy" and "happy" free from anxiety and assigned score 1. The test had the following scores: 1: Very happy and happy (anxiety free); 2: Indifferent (low anxiety level); 3: Sad (Intermediate anxiety level); and 4: Very sad (high anxiety level).

\section{Data Analysis}

To statistically analyze the correlation of results obtained in anxiety tests, the Shapiro Wilk normality test with data of quantitative variables was used and it was found that in all cases, data presented non-normal distribution. Therefore, Spearman's correlation was the most suitable. To compare the anxiety level presented in tests in relation to the age group, the test of independent proportions was used. For all cases where statistical tests were used, $5 \%$ significance was adopted. The software used for statistical analysis was Microsoft Excel 2016 and Past 3.20.

\section{Ethical Aspects}

Prior authorization for participation in the project was requested from parents or legal guardians, with the signing of the Free and Informed Consent Form, and through the child's agreement with the term of consent for minors. This project was evaluated by the Ethics Research Committee on Human Beings and was approved under Protocol No. 2.839.609

\section{Results}

Thirty children were evaluated, $63 \%$ male and $37 \%$ female, belonging to the age group of 4-9 years. The average age of children was 7.01 years. The results showed that, in relation to the absence of anxiety, the modified VPT test identified 21 children (70\%) free from anxiety, the RMS-PS test 27 children (90\%) and in 
the FIS test, 26 children were free from anxiety (87\%). Low anxiety level was diagnosed in the modified VPT test in 9 children (30\%), in the RMS-PS test, 2 children (9\%) and in the FIS test, 3 children (10\%). Intermediate anxiety level was diagnosed by the RMS-PS and FIS tests in only 1 (3\%) of the 30 children (Table 1). Regarding gender, anxiety assessment according to the different tests is shown in Tables 2 and 3.

Table 1. Anxiety assessment in relation to modified VPT, RMS-PS and FIS tests for children aged 4-9 years.

\begin{tabular}{lccc}
\hline \multicolumn{1}{c}{ Anxiety Degree } & Modified VPT & RMS-PS & FIS \\
& $\mathrm{N}(\%)$ & $\mathrm{N}(\%)$ & $\mathrm{N}(\%)$ \\
\hline Free From Anxiety & $21(70.0)$ & $27(90.0)$ & $26(87.0)$ \\
Low Anxiety Level & $9(30.0)$ & $2(7.0)$ & $3(10.0)$ \\
Intermediate Anxiety Level & $0(0.0)$ & $1(3.0)$ & $1(3.0)$ \\
High Anxiety Level & $0(0.0)$ & $0(0.0)$ & $0(0.0)$ \\
\hline
\end{tabular}

Table 2. Anxiety assessment of boys aged 4-9 years.

\begin{tabular}{lccc}
\hline \multicolumn{1}{c}{ Anxiety Degree } & Modified VPT & RMS-PS & FIS \\
& $\mathrm{N}(\%)$ & $\mathrm{N}(\%)$ & $\mathrm{N}(\%)$ \\
\hline Free From Anxiety & $13(68.0)$ & $17(89.0)$ & $17(89.0)$ \\
Low Anxiety Level & $6(32.0)$ & $2(11.0)$ & $2(11.0)$ \\
Intermediate Anxiety Level & $0(0.0)$ & $0(0.0)$ & $0(0.0)$ \\
High Anxiety Level & $0(0.0)$ & $0(0.0)$ & $0(0.0)$ \\
\hline
\end{tabular}

Table 3. Anxiety assessment of girls aged 4-9 years.

\begin{tabular}{lccc}
\hline \multicolumn{1}{c}{ Anxiety Degree } & Modified VPT & RMS-PS & FIS \\
& $\mathrm{N}(\%)$ & $\mathrm{N}(\%)$ & $\mathrm{N}(\%)$ \\
\hline Free From Anxiety & $8(73.0)$ & $10(91.0)$ & $9(82.0)$ \\
Low Anxiety Level & $3(27.0)$ & $0(0.0)$ & $1(9.0)$ \\
Intermediate Anxiety Level & $0(0.0)$ & $1(9.0)$ & $1(9.0)$ \\
High Anxiety Level & $0(0.0)$ & $0(0.0)$ & $0(0.0)$ \\
\hline
\end{tabular}

Spearman correlation was used to compare tests with each other and moderate correlation was observed between RMS-PS and FIS scores (51.01\%), which indicates that MS-PS and FIS tests can measure anxiety the same way. Comparing the modified VPT test with RMS-PS, correlation proved to be non-existent, which indicates that the sample in this study was not sufficiently large to diagnose differences between tests. Correlation was also non-existent between VPT and FIS (Table 4).

Table 4. Correlations between modified VPT, RMS-PS and FIS tests.

\begin{tabular}{lccccc}
\multicolumn{1}{c}{ Variables } & N & Mean (SD) & Median $(\mathbf{D Q})$ & Spearman Correlation & p-value \\
\hline RMS-PS & 30 & $1.1 \pm 0.4$ & $1.0 \pm 0.0$ & $51.0 \%$ & 0.0040 \\
FIS & 30 & $1.1 \pm 0.4$ & $1.0 \pm 0.0$ & & \\
& & & & & \\
Modified VPT & 30 & $1.3 \pm 0.4$ & $1.0 \pm 0.5$ & $-21.7 \%$ & 0.2473 \\
RMS-PS & 30 & $1.1 \pm 0.4$ & $1.0 \pm 0.0$ & & 0.9108 \\
& & & & & \\
Modified VPT & 30 & $1.3 \pm 0.4$ & $1.0 \pm 0.5$ & & \\
FIS & 30 & $1.1 \pm 0.4$ & $1.0 \pm 0.0$ & & \\
\hline
\end{tabular}


To compare the anxiety level presented in tests in relation to the age group, the test of independent proportions was used. Children were grouped into two groups: Group $1=$ children aged 4, 5 and 6 years and Group $2=$ children aged 7, 8 and 9 years. There was no significant difference between proportions of group 1 and group 2 in each test, in the following anxiety degrees: free from anxiety and low anxiety level ( $p>0.05)$. The number of children was insufficient for analysis in the anxiety degrees: intermediate and high anxiety level for the two different groups.

Table 5. Anxiety levels presented in tests in relation to the age group.

\begin{tabular}{|c|c|c|c|c|}
\hline Anxiety Degree & Age Group & $\begin{array}{c}\text { Modified VPT } \\
\text { N }(\%)\end{array}$ & $\begin{array}{c}\text { RMS-PS } \\
\text { N (\%) }\end{array}$ & $\begin{array}{c}\text { FIS } \\
\mathrm{N}(\%)\end{array}$ \\
\hline \multirow[t]{3}{*}{ Free from Anxiety } & Group $1(n=11)$ & $8(73.0)$ & $9(82.0)$ & $8(73.0)$ \\
\hline & Group $2(n=19)$ & $13(68.0)$ & $18(95.0)$ & $18(95.0)$ \\
\hline & p-value & 0.5921 & 0.2557 & 0.0874 \\
\hline \multirow[t]{3}{*}{ Low Anxiety Level } & Group $1(n=11)$ & $3(27.0)$ & $1(9.0)$ & $2(18.0)$ \\
\hline & Group $2(n=19)$ & $6(32.0)$ & $1(5.0)$ & $1(5.0)$ \\
\hline & p-value & 0.8041 & 0.6855 & 0.2557 \\
\hline \multirow[t]{2}{*}{ Intermediate Anxiety Level } & Group $1(n=11)$ & $\mathrm{o}(0.0)$ & $1(9.0)$ & $1(9.0)$ \\
\hline & Group $2(n=19)$ & $\mathrm{o}(0.0)$ & o (0.0) & $0(0.0)$ \\
\hline \multirow[t]{2}{*}{ High Anxiety Level } & Group $1(n=11)$ & $0(0.0)$ & $\mathrm{O}(0.0)$ & $0(0.0)$ \\
\hline & Group $2(n=19)$ & $\mathrm{O}(0.0)$ & $\mathrm{O}(0.0)$ & $\mathrm{O}(0.0)$ \\
\hline
\end{tabular}

When comparing tests in relation to how easy children understand them, the modified VPT test was preferred by $54 \%$, the RMS-PS by $33 \%$ and the FIS by $13 \%$. Regarding attractiveness, the modified VPT test and the RMS-PS were preferred by $40 \%$, respectively, and the FIS by $20 \%$ (Table 6 ).

Table 6. Distribution of test preference regarding ease of understanding.

\begin{tabular}{lcc}
\multicolumn{1}{c}{ Tests } & Ease of Understanding & Attractiveness \\
\hline Modified VPT & $54.0 \%$ & $40.0 \%$ \\
RMS-PS & $33.0 \%$ & $40.0 \%$ \\
FIS & $13.0 \%$ & $20.0 \%$ \\
\hline
\end{tabular}

\section{Discussion}

This work aimed to assess anxiety prior to dental care for children using tests available in literature and to identify the preference of tests by children regarding ease of understanding and attractiveness. The most modern and updated tests were chosen for this work, such as the modified VPT, RMS-PS, and FIS as a classic test $[2,9,14]$.

The search for a better environment for the child at the dental office encompasses several segments, including modern technologies, preparation of the pediatric room to the most current psychological approaches to involve children, whether for dental treatment or for promoting oral health in a more careful and up-to-date way as possible. This is what could be observed in relation to tests to assess anxiety, which have evolved from black and white figures to colored figures and photographs in different studies [8,9,12,13].

Observing the need to update tests for a new generation of children and to compare with other existing tests such as VPT, RMS-PS and FIS, some authors identified strong correlation between scores of VPT and RMS-PS tests, which indicates that the latter can measure child's anxiety in the same way as VPT. Comparing scores between RMS-PS and FIS, the authors found moderate correlation in their study [9]. Data from the present study also pointed out that the scores of RMS-PS and FIS tests had moderate correlation 
(51.01\%). However, when the modified VPT test was compared with RMS-PS, and the modified VPT with FIS, correlations proved to be non-existent. It could be inferred that this finding is possibly due to the fact that the sample in this study is not sufficiently large to observe any correlation.

In the analysis of the anxiety of children who participated in this study, the modified VPT test identified $70 \%$ of children free from anxiety and $30 \%$ with some anxiety degree; the RMS-PS identified $90 \%$ of children free from anxiety and 10\% with some anxiety degree. The FIS test identified $87 \%$ of children free from anxiety and $13 \%$ with some anxiety degree. Also in another study, the authors observed $75.4 \%$, out of a total of 1202 children, free from anxiety using the dental anxiety questionnaire (DAQ) [14]. Another study corroborates the findings of this study when assessing fear and anxiety about dental treatment (DFA) among children aged 3-14 years and found 14.3\% of dental fear according to the facial image scale (FIS), 22.6\% according to the dental fear scale (DFS), and 7.4\% when using the dental subscale (CFSS-DS) [15].

Regarding gender, this study showed similar result for both boys and girls regarding the presence of some anxiety degree. Other authors found $22.68 \%$ of dental anxiety in a cross-sectional study with a group of Romanian students aged 6-12 years and also found no significant differences in dental anxiety scores between boys and girls [16]. In a systematic review of thirty-two articles, it was found that the prevalence of fear and dental anxiety was more frequent in girls [17].

Regarding the age group, there was no significant difference between proportions of group 1 (4.5 and 6 years) and group 2 (7.8 and 9 years) in the present study. In the systematic review above, in addition to assessing the difference between genders, they verified variable age in the investigation of dental fear and observed a decrease in the prevalence of dental fear with increasing age [17]. In the research of other authors, the results showed that an unpleasant previous experience in the dental clinic and the child's age significantly influence behavior during dental care, and it was concluded that dental fear decreases and behavior improves with increasing age [18]. In this study, it was observed that children are familiar to the University Pediatric Dentistry Clinic, which can be an explanatory hypothesis for the lack of significant difference in relation to the presence of dental fear in groups 1 and group 2.

In the present study, the test that was the easiest to understand was the modified VPT (54\%). As for attractiveness, the modified VPT and RMS-PS tests had equal results (40\%). Data in this study differ from other authors who found that the RMS-PS test was the most attractive for $62.7 \%$ of children, followed by VPT $(33.3 \%)$ and FIS (3.9\%) [9]. It could be inferred that the modified VPT test was more attractive to children in the region of this study since they identified more with the test that used colored and funny drawings containing body expressions in addition to facial expressions, compared to the test that used photographs (RMS-PS). For a more in-depth assessment of correlations among tests, studies with larger samples should be carried out.

\section{Conclusion}

The three tests were able to identify anxiety prior to dental care. During the study and through the evaluation of results, it was observed that the identification with the test was proportional to its attractiveness and ease of understanding. RMS-PS and modified VPT tests were the most attractive for children, and the easiest to understand was the modified VPT.

\section{Authors' Contributions}




\begin{tabular}{|c|c|c|}
\hline MFO & (D) $0000-0003-3113-9876$ & $\begin{array}{l}\text { Conceptualization, Methodology, Writing - Review and Editing, Visualization, } \\
\text { Supervision and Project Administration. }\end{array}$ \\
\hline CES & (iD) $0000-0003-3580-8678$ & Formal Analysis and Data Curation. \\
\hline FCLS & (D) $0000-0002-1744-9774$ & $\begin{array}{l}\text { Methodology, Investigation, Writing - Original Draft Preparation, Data Curation } \\
\text { and Visualization. }\end{array}$ \\
\hline WRK & (D) $0000-0002-3396-2869$ & $\begin{array}{l}\text { Methodology, Investigation, Writing - Original Draft Preparation, Data Curation } \\
\text { and Visualization. }\end{array}$ \\
\hline
\end{tabular}

\section{Financial Support}

None.

\section{Conflict of Interest}

The authors declare no conflicts of interest.

\section{References}

[1] Goés MPS, Domingues MC, Couto GBL, Barreira AK. Anxiety, fear and vital signs of the child signs of the child patients. Odontol Clín-Cient 2010; 9(1):39-44.

[Q] Vilas-Boas ADM, Vieira JOS, Diniz MB. Child's behavior and its relationship with the level of maternal-child anxiety during dental care. Pesqui Bras Odontopediatria Clín Integr 2017; 17(1):36-46. https://doi.org/10.4034/PBOCI.2017.171.46

[3] Bottan ER, Lehmkuhl GL, Araújo SM. Dental treatment anxiety: an exploratory study with children and adolescents of a city in Santa Catarina. RSBO 2008; 5(1):13-9.

[4] Felix LF, Brum SC, Barbosa CCN, Barbosa O. Aspects that influence in behavioral reactions of children in dental offices. Rev Pró-UniverSUS 2016; 7(2):13-6.

[5] Klingberg G, Broberg AG. Dental fear/anxiety and dental behaviour management problems in children and adolescents: a review of prevalence and concomitant psychological factors. Int J Paediatr Dent 2007; 17(6):391-406. https://doi.org/10.1111/j.1365-263X.2007.00872.x

[6] Alsadat FA, El-Housseiny AA, Alamoudi NM, Elderwi DA, Ainosa AM, Dardeer FM. Dental fear in primary school children and its relation to dental caries. Niger J Clin Pract 2018; 21(11):1454-60. https://doi.org/10.4103/njcp.njcp_160_18

[7] Pinkham JR. Observation and interpretation of the child dental patient behavior. Pediatr Dent 1979; 1(1):21-6.

[8] Ramos-Jorge ML, Pordeus IA. Why and how to measure child's anxiety in dental enviroment. The modified VPT. JBP Rev Ibero-am Odontopediatr Odontol Bebê 2004; 7(37):282-90.

[9] Shetty RM, Khandelwal M, Rath S. RMS Pictorial Scale (RMS-PS): an innovative scale for the assessment of child's dental anxiety. J Indian Soc Pedod Prev Dent 2015; 33(1):48-52. https://doi.org/10.4103/0970-4388.149006

[10] Buchanan H, Niven N. Validation of a facial image scale to assess child dental anxiety. Int J Paediatr Dent 2002; $12(1): 47-52$.

[11] Ramos-Jorge ML, Marques LS, Pavia SM, Serra-Negra JM, Pordeus IA. Predictive factor for child behaviour in the dental environment. Eur Arch Pediatr Dent 2006; 7(4):253-7. https://doi.org/10.1007/bfo3262561

[12] Venham LL, Gaulin-Kremer E. A self-report measure of situational anxiety for young children. Pediatr Dent 1979; $1(2): 91-6$.

[13] Marques KBG, Gradvohl MPB, Maia MCG. Fear and anxiety previous to dental treatment in children from AcaraúCE. Rev Bras Prom Saúde 2010; 23(4):358-67. https://doi.org/10.5020/2038

[14] Silveira ERD, Goettems ML, Demarco FF, Azevedo MS. Clinical and individual variables in children's dental fear: a school-based investigation. Braz Dent J 2017; 28(3):398-404. https://doi.org/10.1590 / 0103-6440201601265

[15] Rajwar AS, Goswami M. Prevalence of dental fear and its causes using three measurement scales among children in New Delhi. J Indian Soc Pedod Prev Dent 2017; 35(2):128-33. https://doi.org/10.4103/JISPPD.JISPPD_135_16

[16] Popescu SM, Dascălu IT, Scrieciu M, Mercut V, Moraru I, Tuculină MJ. Dental Anxiety and its association with behavioral factors in children. Curr Health Sci J 2014; 4O(4):261-4. https://doi.org/10.12865/CHSJ.40.04.05

[17] Shim YS, Kim AH, Jeon EY, An SY. Dental fear \& anxiety and dental pain in children and adolescents; a systemic review. J Dent Anesth Pain Med 2015; 15(2):53-61. https://doi.org/10.17245/jdapm.2015.15.2.53

[18] Suprabha BS, Rao A, Choudhary S, Shenoy R. Child dental fear and behavior: the role of environmental factors in a hospital cohort. J Indian Soc Pedod Prev Dent 2011; 29(2):95-101. https://doi.org/10.4103/0970-4388.84679 